\title{
The object-oriented design of overhead contact line systems for railway and tram systems
}

\author{
N. Berthold \\ Signon Deutschland GmbH, Germany
}

\begin{abstract}
The design process for overhead contact line systems (OCS) is very complex. Engineers need support for the design task, not only for the simple drawing but also with "intelligent" relations between the single "Objects" of the OCS. Within a period of more than 15 years today's company Signon Deutschland GmbH developed as ELBAS GmbH the tool ELBAS OLACAD ${ }^{\circledR}$ for the design of OCS. The module allows the effective design of OCS for railway, light rail and tram systems in stations and workshops, including complex junctions and operating yards. With the help of this tool more exact results of OCS design can be reached in shorter time. The unique features of ELBAS OLACAD are: all relevant data stored inside the drawing (no additional database-system required), usable for railway, light rail and tram OCS, 2D and 3D representation in the same drawing, integrated static calculation for mast and foundation base accessories (EN 50119:2009 [1]).

Keywords: overhead contact line, catenary, design and construction, CAD-tool, software, static calculation, railway, light rail, tram
\end{abstract}

\section{Introduction}

The design of overhead contact line systems (OCS) is very complex due to many different requirements from national and international standards, construction specifications and rules of the different infrastructure operators as well as due to the complexity of OCS. The design engineer must know the different regulations and use them without any error, since the OCS has a substantial influence on the safety of the whole transportation system. 
In addition the requirements of the customers always continue to rise demanding detailed design and shorter designing times with complexity of the projects rising at the same time.

Design or also project engineering takes place at present predominantly manually under use of different CAD programs such as AutoCAD ${ }^{\circledR}$ or MicroStation $^{\circledR}$, in order to call only two larger representatives.

In the meantime some extensions exist to these CAD programs, which are to support the engineer in different depth by use of pre-defined symbols and properties as well as the partial automation of the designing procedures. Large installation companies developed tools, which used them predominantly for the preparation of building projects, in which their special methods of construction and their own fittings and components are used.

The software package ELBAS OLACAD ${ }^{\circledR}$ presented here is an add-on for AutoCAD, which was developed by engineers of today's Signon Deutschland $\mathrm{GmbH}$ for the project engineering of OCS.

\section{Target of development}

The project engineering tool was developed under the following premises:

- It should be applicable both for the suburban traffic (light rail and tram) and for long-distance traffic (railway).

- It is to make a manufacturer-neutral design possible. In addition different defined methods of construction are to be converted, with which the bases are deposited in specific databases.

- There has not to be restriction regarding any designs. If a design were not realized yet, an additional adjustment must be possible with justifiable means.

- The designing tool is not only to make the design possible of free tracks, but also complicated projects like large railway stations, workshops, or in the suburban traffic crossings within the road range.

- Different detail depths are to be able to be used to make planning possible for all project phases.

- The design tool is to make construction phase planning possible.

A further, substantial premise was the principle that the tool represents a support for the designing engineers; however it cannot replace them. Software is only so good, as the way it was programmed and the experience which is deposited in it. It was not a goal of limiting the software from the beginning. Thereby grows however the responsibility of the user, who must check the output for plausibility.

An explained goal was also not to develop a completely new program but to extend existing CAD-programs. Due to widespread use, the decision fell on AutoCAD. This program is common among designers both in railway and in the suburban traffic, in Germany and abroad and not only used for OCS, but also for other fields of design and construction. The idea consisted of creating a project engineering tool which uses the programming basis of AutoCAD, but supplements it with overhead line-specific elements. Thus it should be also 
achieved that AutoCAD experienced planners will be able to deal with the tool after relatively short training period. Since some companies are also using different project engineering programs, such as MicroStation, a conversion between these systems is to be possible.

ELBAS OLACAD developed from the desires of engineers to have the support in their daily work. In the program are invested over 15 years of experiences. A majority of the necessary programming work was made directly by engineers specialized in the design of OCS. In the meantime the program support and programming take place additionally by software developers. Thus the professional employment is guaranteed in other companies also with increasing complexity of the progressive software development.

\section{Design of overhead Contact lines}

\subsection{Basics}

The use of AutoCAD essentially consists of handling objects and the input of commands. Objects, for example line, circle, square and text have properties and can be linked among themselves. Such properties can be for example line strength, colour, filling, position, or font size. Exactly this determines the approach with ELBAS OLACAD: It defines new objects as for example contact wire, clamp, cantilever, mast and foundation (Figure 1).

The advantage of the use of these defined objects exists in the use of the special properties belonging to it. By the combination of the different objects in the context of project engineering reciprocal effects and combinations develop also between the properties of the objects. These become, to the extent necessary, iterative balanced. If one changes for example a mast position, immediately forces, geometrical information and further variables computes again and are represented. It is possible to recognize immediately and without further tools or designing steps the influence of changes on the graphic result of design or also the static loads.

Finally from a variety of connected elements the OCS is developed and deposited in a CAD plan.

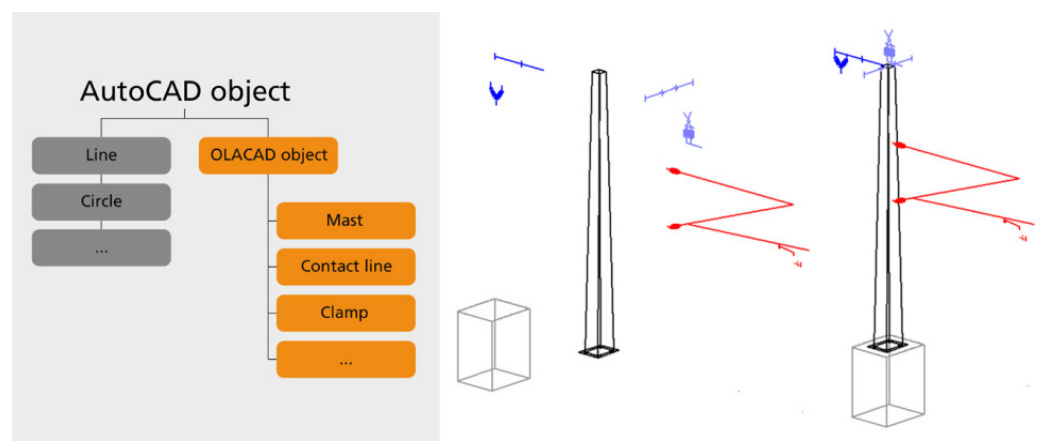

Figure 1: AutoCAD objects and ELBAS OLACAD objects. 
The characteristic therein is that this CAD plan contains all properties of its "intelligent" elements. It means any plan designed with ELBAS OLACAD contains not only the graphic elements for representation of design but also all their data and specifications.

This approach is also a condition to be able to design both in the $2 \mathrm{D}$-view as well as three-dimensional. The elements have all information necessary for it. As by-product, so to say, result from it also longitudinal and cross sections and this at any point. Thus a first insight of the future appearance of the facility can be already taken in early planning phases. In this way conflicts with complicated installation situations are very simple to recognize and solve.

Since the design tool is an add-on of AutoCAD, all usual AutoCAD commands are to the engineer further at disposal. The commands are selected by menus, in those either the properties of the objects are to be entered or the properties from a library can be adapted (Figure 2).

If ELBAS OLACAD is loaded, all properties remain in the plan and the functionality of design is complete. However also without the use of ELBAS OLACAD files can be opened in AutoCAD and be overlaid and exported with data of other designers.

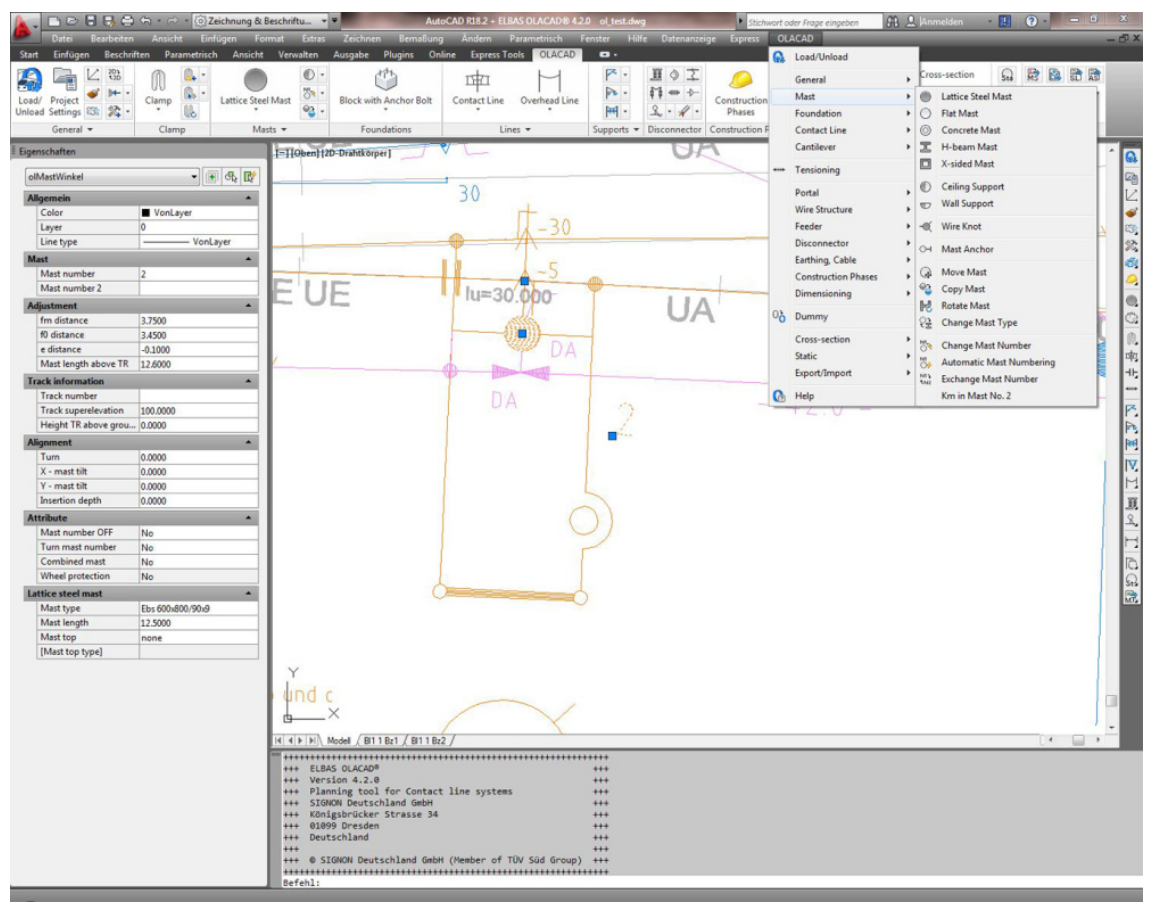

Figure 2: Menu of ELBAS OLACAD, ribbons, properties and toolbox. 


\subsection{Requirements}

Different plans serve the design engineer of the OCS as basis. Beside the indispensable track-geometrical projects this can be:

- Inventory plans

- Cable layout plans

- Plans for drainage facilities

- Signal layout plans

- Land register plans

- Transverse profiles

- Plans for superstructures

- Design plans of civil engineering i.e. bridges, viaducts, tunnels or platforms.

The more and more exact documents are present all the more precisely is the OCS design. Ideally the plans are already present in a file format fitting for AutoCAD and can thereby simply be insert into the reference collecting file, called a base-plan.

In order to be able to use the 3D-functionality of ELBAS OLACAD correctly, the reference plans in particular from bridges and other civil engineering structures concerned should be likewise as 3D-design. If this is not the case, the engineer can insert simplified 3D-Polygon at the points into the design as further reference.

With all advantages of a maximum design support it must not be forgotten that site visits often are necessary to facilities with existing constructions in addition to the inventory plans.

\subsection{Project engineering process}

The following depiction gives only one idea of the process of project engineering, since this can deviate project-specifically or in dependence of the quality of the original data and the design objective. A new project always starts with a new empty file based on template. The primary conditions of the project, which have an influence on the results of the design has to be defined. All settings are generally valid for the project, can be changed however at any later time. As examples may be mentioned:

- Definition of construction phases,

- Project settings for the used OCS,

- Information on the environmental influences and

- Load cases for the static views, which are to be considered.

The defined construction phases (Figure 3) have influence on the (coloured) representation of the objects in the plan regarding the time of their installation or their dismantling. Thus a later change in the fundamental construction phases can lead to additional revising of the plan. Therefore a meaningful allocation of the construction phases which can be planned is favourable at the start of the project. 


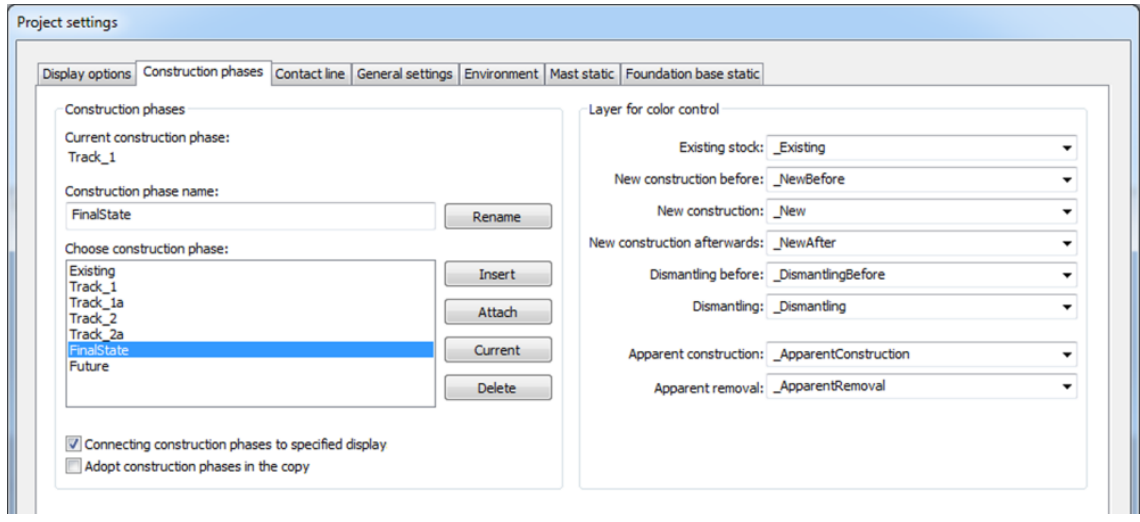

Figure 3: Definition of construction phases.

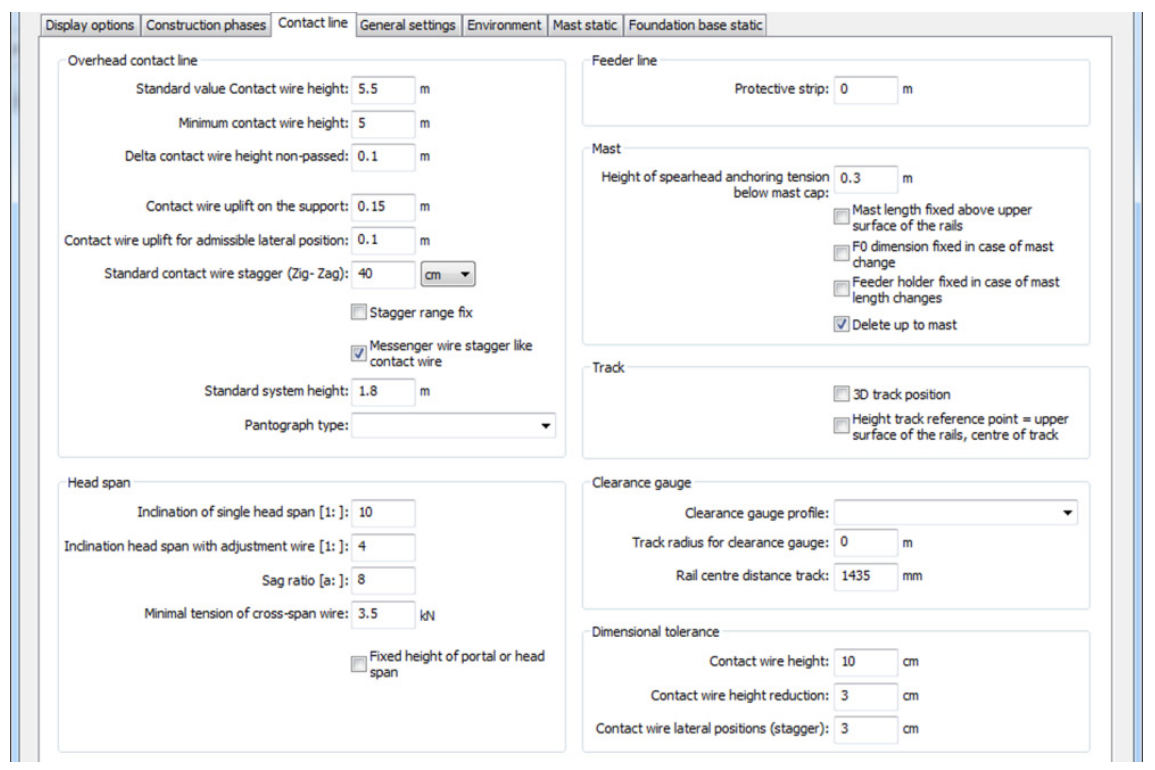

Figure 4: General settings for OCS.

Via the register "Contact line" settings are made which specify the basic characteristics of (first the basic characteristics of all from Figure 4) the overhead line and objects which will be created in the context of design. Also these can generally still be changed later or be specified by overwriting of the characteristics of individual design objects for specific installation conditions, i.e. for system height reductions. Here the high flexibility of the tool shows up for the first time. The user is not dependent on the use of, certain firmly given 
value combinations which are given by a certain design, rather all values can be combined freely. For the meaningful employment of these value combinations the pronounced expertise of the engineer is necessary for the connections within the OCS.

Figure 5 shows the possibilities for the regulation of the environmental conditions which can be considered to the verification of the usability, in particular for the wind elevation, evidence of (electrical) distances or static calculations. The combination with settings to the partial factors of safety which can be used with individual load cases (Figure 6) results in the possibility of making complete static proofs for the overhead line support points.

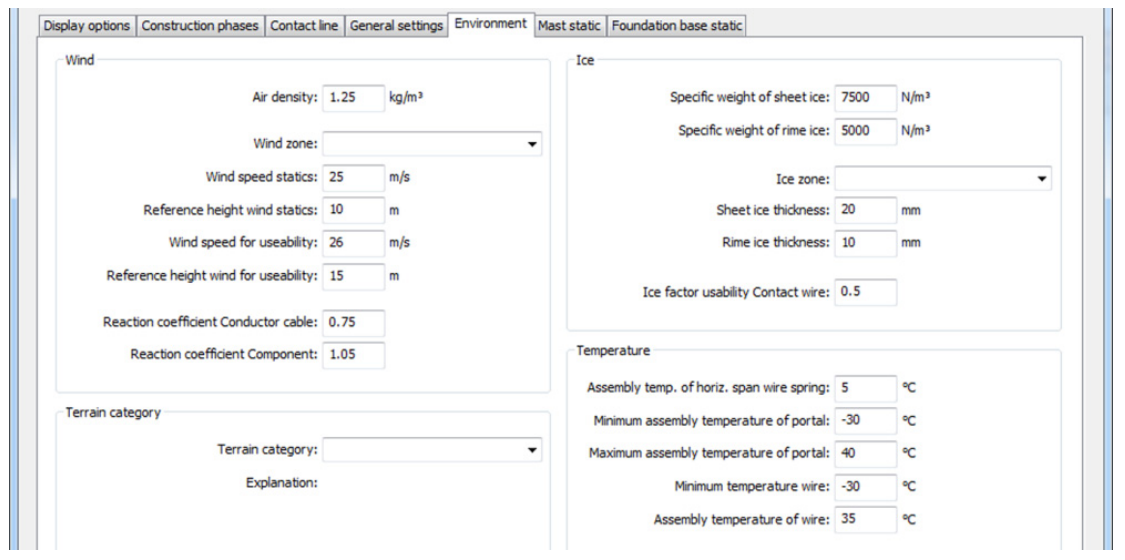

Figure 5: Environmental settings.

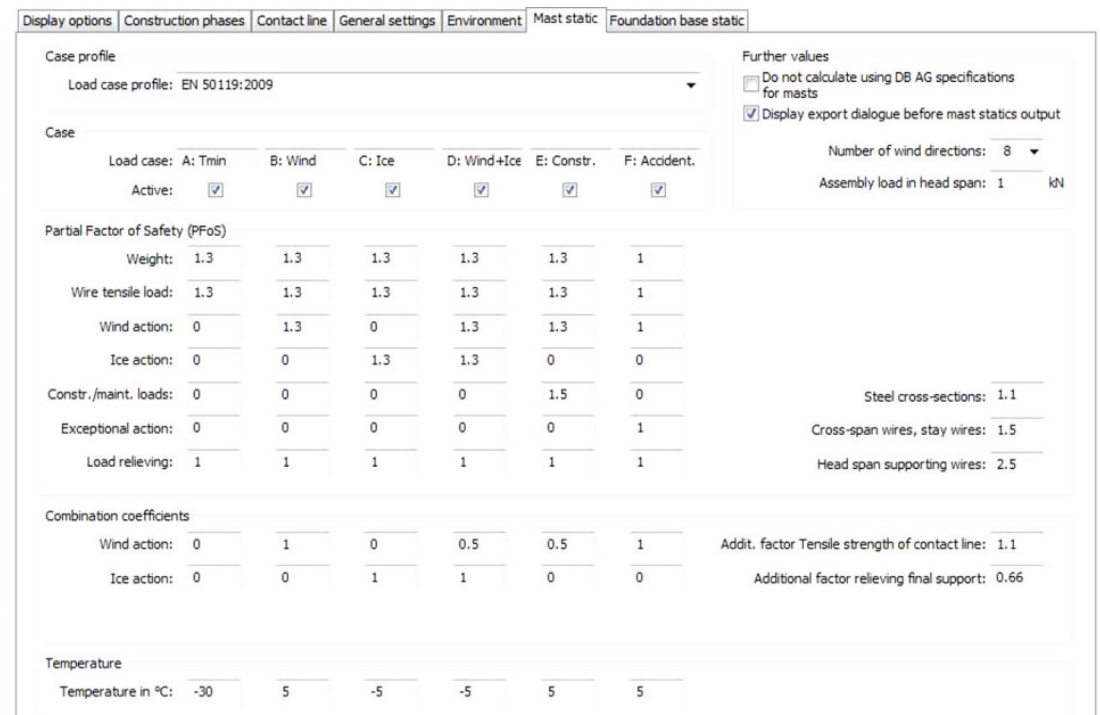

Figure 6: $\quad$ Partial safety factors for static calculation acc. EN 50115. 
In both masks again complete default sets from established standards are selectable, which can be overwritten separately by project-specific pre-set properties. Even changes of the normative defaults would be possible. The engineer has thereby also the full flexibility available. I.e. he is able to recalculate existing OCS with at the time of their establishment valid standards. After the input of some further fundamental and informative project settings the base-plan created on the beginning can be inserted as reference. The double correlation of the basic reference plans makes it possible later on problem-free to implement distortions with different factors for each dimension.

Planning in the 2D-Modus generally begins with the layout plan. A fundamental goal of the OCS design is to put the contact wire into an optimal situation to the pantograph. Therefore one begins with planning at the clamping points of the contact wire. In the properties of the clamps, which represent the later connection to supports such as cantilever and head-span wires, are the support specific characteristics, as for example contact wire and system height, use and execution of stitch wire as well as the zig-zag are defined. Beside standard catenary, single contact lines and conductor rails can also be selected and designed.

The clamps are distributed by the designing engineer on the basis of the points of constraint, as i.e. under and at buildings, on level crossings and turnouts. After the following "pulling of the contact wire" this is shown distorted as a stringing plan and as a grading plan. The distortions of the gradient of contact wire (including the referenced track plan) as well as the representation of the wind deviation as a function of the project settings or pantograph profile are helpful tools to find optimal results (Figure 7).

Due to the 3D-models of the OCS switching into the longitudinal section is possible at any time, in order to consider height profile of the catenary, for example at bridges. Longitudinal distortions for the optimization of the situation and for evidence of (electrical) distances are possible by mouse-click also here. For the proof of the electrical minimum distances thereby the gradient of the different wires in gradient cases under certain environmental condition, as ice loading or abrasion of the contact wire, can be represented.

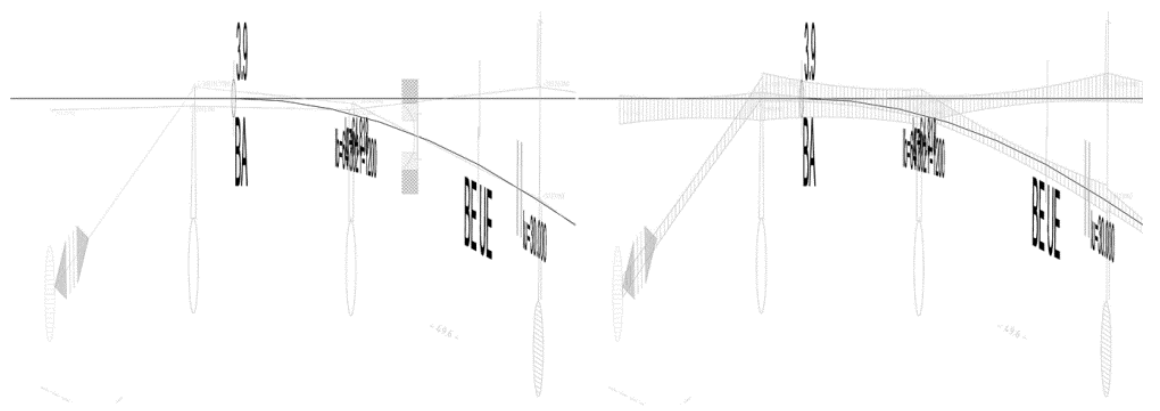

Figure 7: Distorted drawings. 
Subsequently, the mast locations can be specified. On basis of defaults and local conditions now supports assigned to the clamps. This can be e.g. single or multi-track cantilever, portals or headspans.

After the adjustment of the mast locations lengthwise to the track the classification of the foundations and masts in the area follows. The design tool makes here the link possible of each mast location or pair of masts with a designed or surveyed cross-section profile. On basis of this mast classification the determination of the mast length can be done. The determined length is assigned to the object mast as characteristic and is shown full-scale in the cross profile (Figure 8 ). The changes made in the cross-section profile are effectively shown thereby also in the 2D-layout.

After supports and possibly feeder lines, disconnectors, connecting wires and further equipment at the mast were specified, the selection of the masts and foundations with appropriate static calculations takes place. The new design requirements of the EN 50119 [1] are considered. ELBAS OLACAD summarizes all forces and moments influencing at the mast. Basis for this are the values of the environmental condition and the load cases which are given in the project settings. The sums of the loads at the mast are shown to the designer in the comparison to the given strength of the mast in a diagram (Figure 9). It is thus immediately recognizable whether the selected type of the mast from view of the statics possesses has sufficient dimensioning.

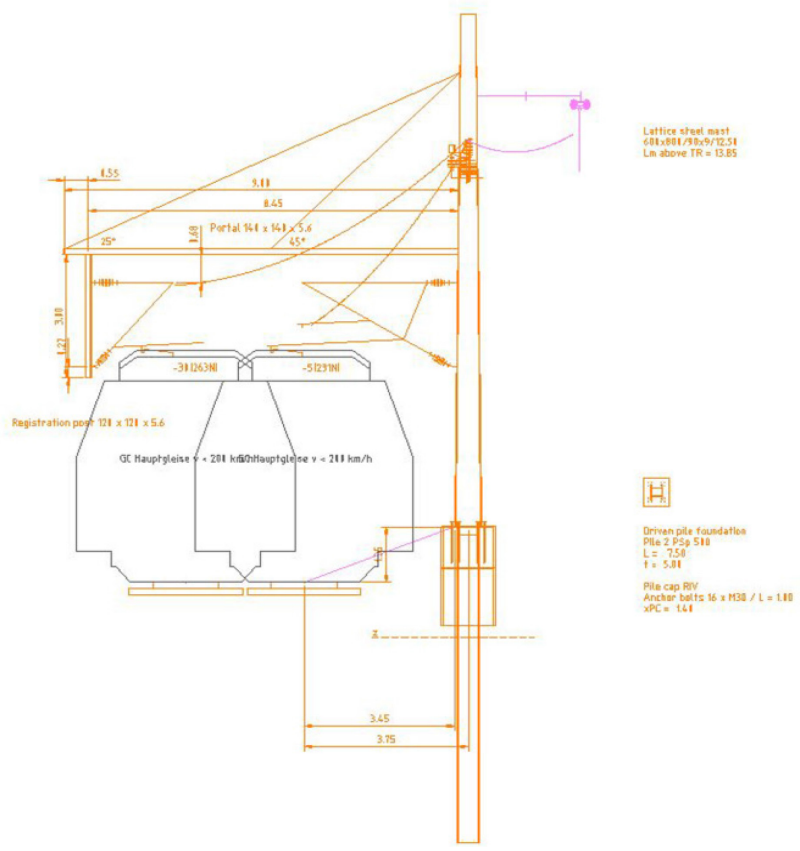

Figure 8: Cross-section drawing. 


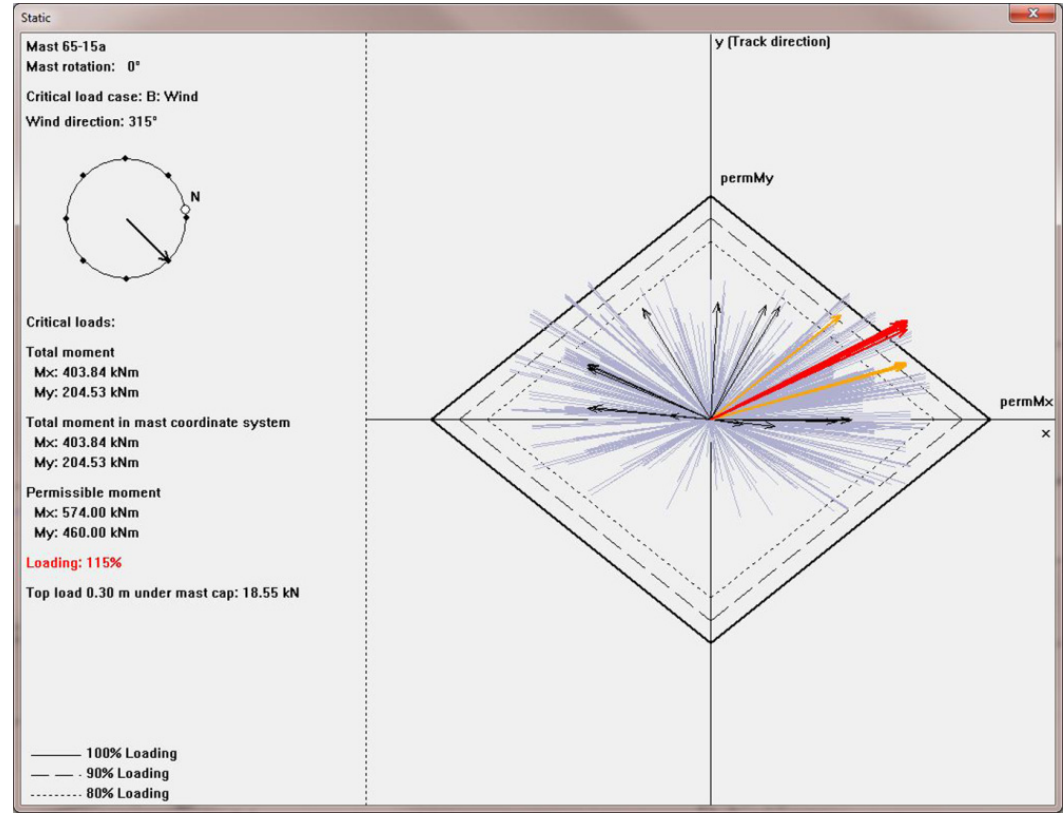

Figure 9: Result of static calculation for mast acc. EN 50119.

The results of static calculations exported by the program can be submitted for examination.

For construction phase planning a certain lifetime can be assigned to each element in its specific properties according to the construction phases of the project. If several construction phases are to be worked on and represented in the context of design, then successively the individual construction phases are to be selected as active construction phase. The individual design steps are to be repeated then for each construction phase.

The individual objects are represented, depending upon object situation in the selected construction phase, in different colours as:

- Existing stock

- New built before the actual phase

- To build in this phase

- To build in a future phase

- Already disassembling before

- Foreseen for disassembling in this phase

All this information is integral components of the ELBAS OLACAD file.

\subsection{Design results}

The design results can be exported in different way.

By special dimensioning points at the individual objects the necessary dimensioning can be produced for the correct points of reference likewise very 
fast. The following edition can export for each construction phase also value tables apart from the position or layout plans and cross-section profiles. That can be for example catenary tables and tables for the traction current feeders. In addition, coordinate tables for the establishments of mast or complete mast and foundation tables after customer defaults can be produced from the designs of ELBAS OLACAD with few mouse clicks. For the export of the digital plan documents after $C A D$ interface descriptions of different customers like for example with the existing standard Ril 885.9906 [2] of German railway (DB $\mathrm{AG})$, there are functions already pre-programmed in ELBAS OLACAD.

From the 3D-model can be produced views from arbitrary angles. For complicated cases of assembly detailed assembly drawings can be provided without large expenditure, which describe the thoughts of the designer to the contact line mechanic.

The export of the verification for the statics comes directly from the program in a PDF/A document. This contains all necessary input and output data and so makes it possible for the examiners of the statics to check with own methods.

\section{Examples}

With the use of ELBAS OLACAD in past years numerous projects for railway and tram with different methods of construction were provided. There were so far hardly circumstances, which could not be solved. This particularly benefitted the circumstance that programming and planning are very closely connected.

Exemplarily shows Figure 10 the 3D-view of a railway station entry and Figure 11 for the tram a fully equipped crossing. The excellent characteristic is the representation of the necessary construction phases. Both examples are today realized.

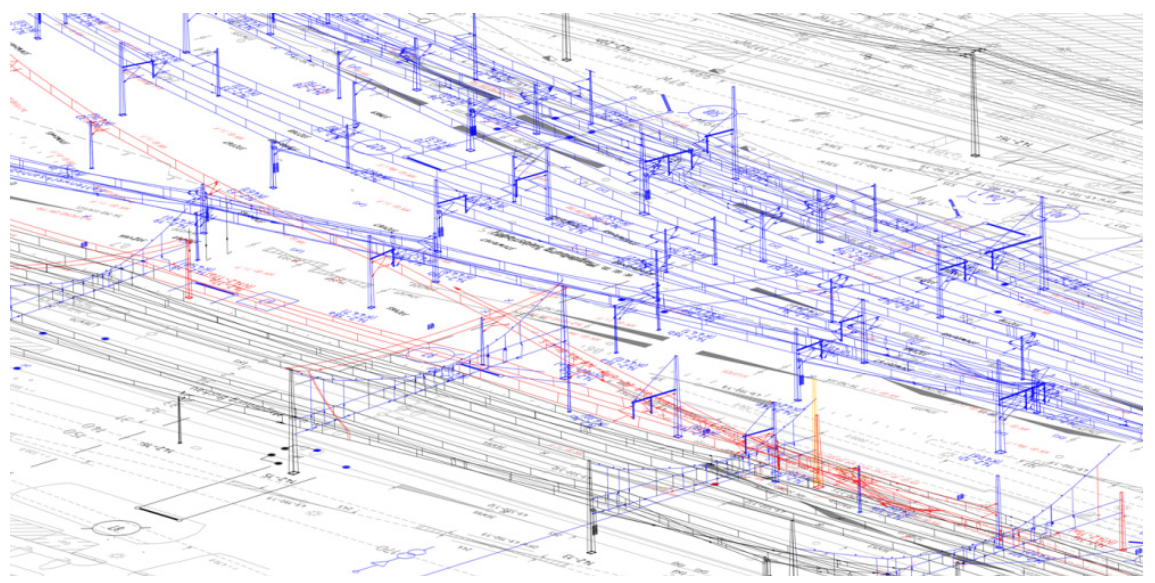

Figure 10: Partial 3D-view of a railway station. 


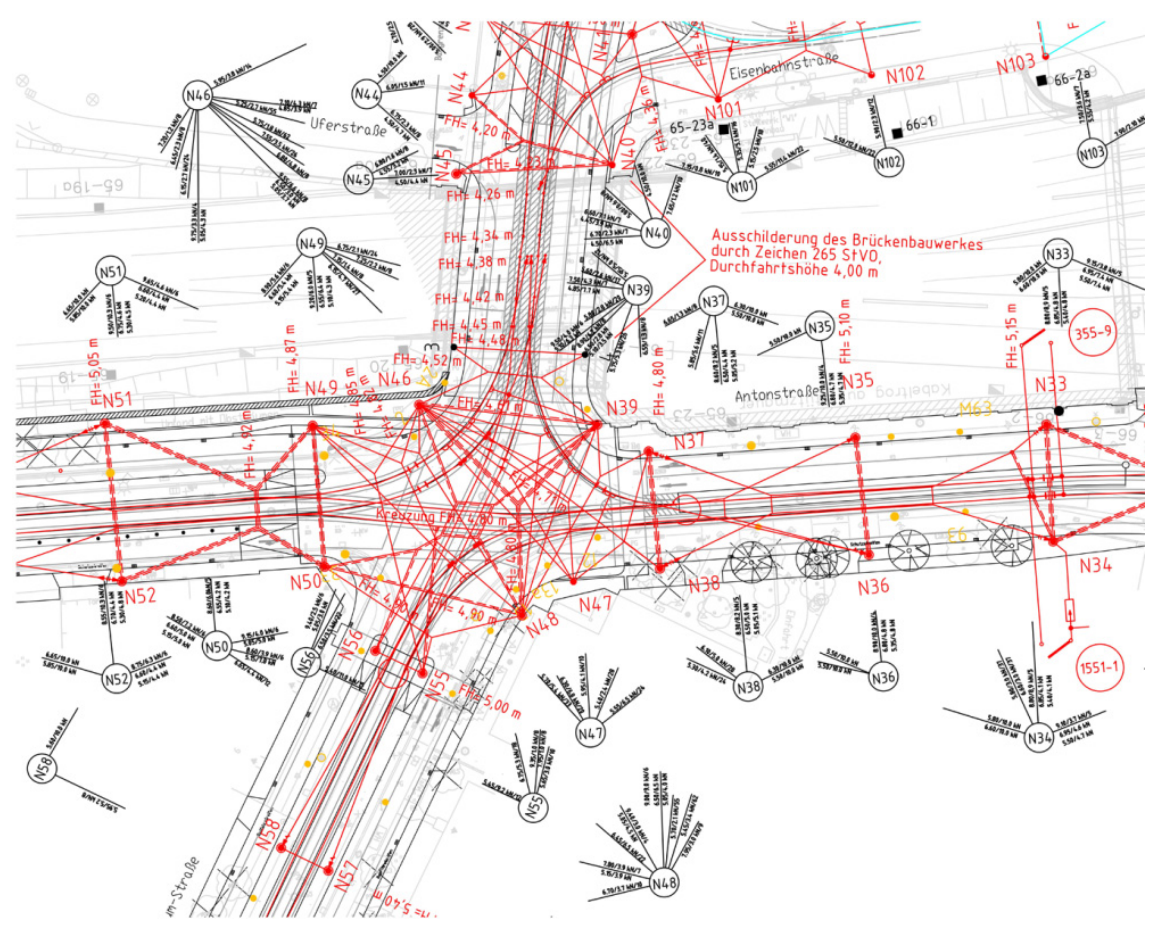

Figure 11: Tram on fully equipped road crossing.

\section{Conclusion and perspective}

The program is in use since some years with OCS designers, who were not directly concerned with the programming of ELBAS OLACAD. Thus the fundamental usefulness was proven through third. In connection with a realization of a project the product was licensed also for use by foreign companies.

The development and maintenance of ELBAS OLACAD is a constant process. Adjustments based on the newly published versions of AutoCAD and the operating system as well as safety updates or function optimizations are supplied over regular updates to the customers. The inclusion of further functions into the capacity of the software is based on the desires of the users.

\section{References}

[1] EN 50119:2009/A1:2013: Railway applications. Fixed installations. Electric traction overhead contact lines.

[2] Deutsche Bahn AG, Richtlinie Ril 885.9906: Bahngeodaten; Schnittstellenbeschreibung Elektrotechnik, Teilbereich Oberleitungsanlagen. 